\title{
Green Innovation Mode under Carbon Tax and Innovation Subsidy: An Evolutionary Game Analysis for Portfolio Policies
}

\author{
Shengzhong Zhang ${ }^{1}$, Yingmin $\mathrm{Yu}^{1}{ }^{1} \mathbb{D}$, Qihong $\mathrm{Zhu}^{2, *}{ }^{2}$, Chun Martin Qiu ${ }^{3}{ }^{\mathbb{C}}$ and Aixuan Tian ${ }^{1}$ \\ 1 School of Economics and Management, Chang'an University, Xi'an 710064, China; \\ szzhang@chd.edu.cn (S.Z.); yingminyu@chd.edu.cn (Y.Y.); 2017123039@chd.edu.cn (A.T.) \\ 2 School of Business Administration, Shanghai Lixin University of Accounting and Finance, \\ Shanghai 201620, China \\ 3 Lazaridis School of Business and Economics, Wilfrid Laurier University, Waterloo, \\ ON N2L 3C5, Canada; cqiu@wlu.ca \\ * Correspondence: zhuqihong@lixin.edu.cn
}

Received: 20 December 2019; Accepted: 9 February 2020; Published: 13 February 2020

\begin{abstract}
Previous literature has shown that manufacturers' choices between radical and incremental green innovation modes can greatly impact the tradeoff between industry growth and carbon emission reduction. Yet, how the government can motivate manufacturers to implement radical green innovations to reduce carbon emission is unclear. In this paper, the researchers construct an evolutionary game model to analyze the joint impacts of carbon tax and innovation subsidy on manufacturers' choices of green innovation mode. We derive the conditions for manufacturers' stable strategies. Based on those results, we find that four factors-carbon tax, innovation subsidy, consumer green preference, and manufacturers' capabilities of absorbing and adopting new technologies-may facilitate the choice of radical innovation. Furthermore, we conduct numerical simulations to verify the theoretical results, and further illustrate how the synergy of carbon tax rate and subsidy level affects the evolution of the green innovation mode choices. Specifically, we demonstrate the superiority of portfolio policy in the early stage of green innovation over single policy. In contrast, in the later stage, it is carbon tax but not innovation subsidy that remains effective. We discuss the insights for the government to formulate appropriate environmental policies to effectively promote the adoption of green innovation and reduce carbon emission.
\end{abstract}

Keywords: green innovation; carbon tax; innovation subsidy; consumer green preference; evolutionary game

\section{Introduction}

In the past few decades, excessive carbon emission and the consequent climate change have become major concerns around the world [1]. As a result, governments in most countries have adopted environmental regulations or laws to limit greenhouse gas emission [2]. Since manufacturing sectors are the main emission sources [3], governments have targeted them by implementing various regulatory tools such as carbon taxes $[4,5]$ in the hope that manufacturers are given pressure to reduce carbon emission.

In addition to the pressure from government regulations, manufacturers also need to address relevant changes in consumers' preference. Researches find that consumers with green preference are willing to pay higher prices for products with lower carbon emissions [6,7]. Therefore, consumer green preference has become an important factor affecting manufacturers' decisions in business operations [8-11]. 
An effective solution to deal with both government pressure and to appeal to green consumers is to implement technologies that help produce more environmentally friendly products. Manufacturers achieve technological progresses through the adoption of so-called green innovations. Based on green innovations' respective influence on the markets and/or products [12,13], there are two modes of green innovation adoption, namely, radical innovation mode and incremental innovation mode. Different innovation modes come with different risks and costs. Radical innovations usually are riskier and require more $R \& D$ investment, but they can improve the green performance of the products more effectively. In comparison, Incremental innovations deliver limited green performance improvement but cost less. Manufacturers thus face the trade-off between costs and benefits when deciding their green innovation mode. Although research has shown that green innovations are positively related to corporate competitiveness and performance [14], many manufacturers still hesitate to develop or adopt radical green innovations due to the associated high R\&D spending and production costs, which they believe will weaken their competitiveness [15].

Manufacturers' choices of green innovation mode affect not only their own performance, but also the likelihood of achieving emission reduction goals set by governments. For instance, the Chinese government has set a target of $60 \%$ to $65 \%$ of $\mathrm{CO}^{2}$ emission reduction per unit of GDP by $2030[16,17]$. However, the high risk of significant $R \& D$ costs, knowledge spillover, and the positive externality of green innovations are all likely to result in manufacturers' hesitation toward developing and adopting radical green innovations [18]. As a result, these manufacturers will, at most, implement incremental innovations, such as green packaging for their products. This will slow down the progress of "go green" in the manufacturing industry and undermine the goal of carbon emission reduction.

As some empirical research has found that a manufacturer's choice of green innovation mode is affected by various internal and external factors [19], the government may guide and encourage manufacturers to choose radical innovations through policy tools beyond imposing pressure. In this paper, we study the joint impacts of two tools-carbon tax and innovation subsidy-on manufacturers' choices of green innovation mode. Specifically, we model a portfolio policy where that the government imposes carbon tax on a manufacturer's products but provides subsidy on the investment cost to promote green innovation. Manufacturers respond accordingly, given the government policies as well as consumers' green preference and market competition. Taking into account the manufacturers' capabilities of adopting new technologies [20,21], we obtain multiple evolutionary stable states with the same amount of R\&D investment and identify the optimal results for carbon emission reduction.

This paper contributes to the literature by filling two research gaps. The first gap is that most previous studies evaluate only individual policies. In comparison, this paper investigates a more realistic setting where the government implements multiple policies that offer incentives as well as impose pressure. Hence, it explores the possible synergy among a portfolio of government policies. The second gap is that most existing studies focus only on the interaction between the government and enterprises and ignore the market factors such as consumers and competitors. In comparison, this paper considers market factors such as consumer preference and peer competition, since the decision of competitors and the market environment are also important factors affecting corporate decision making.

Methodologically, this paper contributes to the literature by adopting an evolutionary game theory approach. This approach allows researchers to model dynamic changes in the environment rather than static ones while taking into account the bounded rationality of decision makers and information asymmetry. Although such an approach mirrors an imperfect image of the real world, it helps researchers focus on the most important factors without the distraction of many peripheral things. The analyses in this paper serve as a sketch map—not precise enough for navigation, but useful enough for exploration.

The rest of this paper is structured as follows. Section 2 reviews the related theories and the literature. Section 3 presents the problem and basic assumptions and analytic results. Section 4 conducts numerical analysis to verify the analytic results and illustrate how various parameters impact 
the evolutionary path. The conclusions and discussions of our study and potential policy insights as well as future research directions are provided in Section 5.

\section{Literature Review}

In order to better illustrate the motivation and research background of this study, the relevant literature is reviewed from three aspects-the impact of environmental policies on manufacturer green innovation, green innovation mode, and applications of evolutionary game theory.

\subsection{Environmental Policies and Their Impacts}

Environmental policies consist of regulations issued by governments at different levels [22], which can be divided into command-controlled or market-incentive regulations, but with a common purpose of reducing carbon emissions and protecting the environment [23]. Zhao et al. [24] used the panel data of high-emission manufacturers from 2007 to 2012 and showed that environmental regulation plays a positive role in promoting manufacturer innovation, but the increased external cost negatively impacts the competitiveness of these manufacturers. Krass et al. [25] studied the impact of carbon taxation on a monopoly's adoption of low-emission production technologies. Hinloopen et al. [26] believed that, due to the positive externalities and high-risk characteristics of innovation, the government needs to offer companies R\&D subsidies as incentives. Wang et al. [27] comparatively analyzed the incentive effects of different subsidy policies such as product subsidies and R\&D subsidies on green endeavors at different stages of manufacturing.

The Porter hypothesis first proposed that environmental supervision can promote green innovation in manufacturers under appropriate conditions [28]. In recent years, many scholars have shown that when manufacturers choose not to carry out green innovations by themselves, environmental regulations from the government can give them incentives [29]. This subsection focuses on the effect of market-based environmental regulations, especially the impact of carbon tax and government subsidies on corporate green innovation.

Some researchers demonstrated the importance of government intervention in green technology diffusion and adoption. For example, Huang et al. [30] studied the impact of green loan scale and government green subsidies on corporate green innovation and demonstrated the effectiveness of government subsidies to promote green innovation and environmental protection. Van Leeuwen and Mohnen [31] demonstrated the positive impact of environmental regulation on corporate innovation through empirical research on Dutch manufacturing companies. Research also shows that governments can encourage corporate green innovation through subsidies to improve the environment more directly [32-34]. For instance, Wanting et al. [35] studied the evolution of firms in the face of dynamic tax and static subsidies, static and dynamic subsidies, dynamic taxation, and dynamic subsidies. They showed a more pronounced incentive effect of bilateral dynamic tax and subsidy mechanisms on the manufacturers' adoption of low carbon technology. Xu et al. [36] proved that an manufacturer will adopt radical innovation only if it leads to positive net income.

\subsection{Green Innovation Mode}

Green innovation is an important approach for manufacturers to minimize or eliminate the negative impact of their production and operations on the environment [37]. At present, green innovation has no uniform definition in the literature. Eco-innovation, environmental innovation, sustainable innovation, and green innovation differ little in nature and can be used interchangeably [38]. Chen et al. [39] define green innovation as innovation in green product design or process improvement, including technological innovation for energy conservation, waste recycling, pollution reduction, and corporate environmental management. Green innovation can be classified into radical innovation and incremental innovation based on its impact on existing products or industries. Radical innovation greatly changes the product performance or production process and can affect the green development of the entire industry; incremental innovation only brings limited changes in product performance or 
production processes [12,13]. As we focus on the degree of green innovation of manufacturers, we adopt the classification of radical innovation and incremental innovation in this study. For more alternative definitions and classifications of green innovation, readers are referred to Schiederig et al. [38].

\subsection{Applications of Evolutionary Game Theory}

Manufacturers cannot make optimal decisions at once. Hence, following the literature, this study adopts evolutionary game theory to construct an evolutionary game model. Evolutionary game theory starts from the theory of biological evolution. One of its underlying principles is that, due to information asymmetry and dynamic changes in the environment, all decision makers are bounded rational [40]. Thus, they cannot make optimal decisions at once. Instead, they adjust their strategies as time goes and reach the game equilibrium after multiple repeated games. As a result, institutional factors, environmental factors, and competitors' decisions will have an impact on the choice of manufacturers' equilibrium strategy. Evolutionary game theory allows repeated base games, and the decision makers thus could adjust their strategy with the changing of environment obtain a satisfactory strategy rather than an optimal decision through dynamic decision-making process. It has been widely used in the field of economics and management to study the interaction among decision makers [41] and is more suitable to study the enterprises behavior under the government regulations and policy because the enterprises need a long period to adjust the policy environment changing and find the most profitable strategy for their development. Zhu et al. [42] uses evolutionary game to analyze how government penalty and subsidy influence green supply chain management. Zhao et al. [43] studied the impact of government incentives such as direct subsidies and tax credit on whether companies adopt carbon emission labeling schemes. They proved that the combination of direct subsidies and tax credit is better than an individual policy. Mahmoudi et al. [44] employed a two-population game to analyze how different combinations of subsidies and carbon taxes impact the manufactures' use of green technology for production and the retailers' choice of two marketing strategies in a supply chain.

\section{Model and Analysis}

\subsection{Problem Description and Model Assumptions}

This paper considers a market of homogeneous products with multiple manufacturers and a group of consumers who have a certain level of green preference. These manufacturers face both carbon tax and green innovation subsidy when choosing their green innovation mode. Other factors influencing their choices include consumer green preferences and market competition.

Competing manufacturers in the same industry with different green innovation capabilities are divided into two groups to participate in the evolutionary game, where Group 1 consists of manufacturers with green innovation capability advantage and Group 2 consists of manufacturers with green innovation capability disadvantage. Their products differ only in terms of their carbon emissions. Moreover, green innovation modes differ in terms of emission reduction effects and the investment needed. For simplicity, we assume that the two innovation modes have identical unit production $\operatorname{cost} c$, as assumed in the literature [36,45]. We further assume that manufacturers who choose radical innovation can change the status quo of the industry, and hence, have the first-mover advantage. Manufacturers who choose incremental innovation are followers. Because manufacturers are bounded rational, they need to constantly learn and adjust their strategies and decisions over time and eventually reach an evolutionary stable state. The strategy sets of two groups are (radical innovation, incremental innovation). Therefore, there are four strategic combinations in the system: (radical innovation, radical innovation), (radical innovation, incremental innovation), (incremental innovation, radical innovation), and (incremental innovation, incremental innovation).

The market clearing price is $p=a+\theta w_{i}-Q$ to incorporate the green preference of consumers [46,47], where $Q=q_{1}+q_{2}$ is the sales quantities of the products, $i=1$, 2. Following the classic $A-J$ model [48], 
the investment required for green innovation is $C_{i}=k_{i} w_{i}{ }^{2} / 2, i=1,2$, where $k_{i}$ is the green innovation cost coefficient. Hence, $k_{i}$ represents the innovation capabilities such as knowledge absorption and application ability of these two manufacturer groups. The larger the $k_{i}$, the smaller the innovation capability of the manufacturer group, and the greater the need of capital investment to achieve the same emission reduction. This assumption is in line with Amir [49] and Matsumura and Matsushima [50]. Further, let $k_{2}=k_{1}+\Delta k$, where $k_{1}$ and $k_{2}$ are the green innovation capability of manufacturer Group 1 and 2, respectively. Moreover, $\Delta k>0$ reflects the fact that Group 1 has innovation capability advantage over Group 2. $w_{1}$ is the unit product emission reduction for the radical innovation, and $w_{2}$ is the unit product emission reduction for the incremental innovation where $w_{1}>w_{2}$.

The coefficient of the innovation subsidy is set as $r$, where $0 \leq r \leq 1$. For example, if the manufacturer Group 1 chooses radical innovation, the required capital investment is $C_{1}=k_{1} w_{1}^{2} / 2$ without innovation subsidy from the government. With subsidy, the investment required is (1-r) $k_{1} w_{1}^{2} / 2$. Before green innovation, the carbon emissions per unit product of the two manufacturer groups are identical and denoted by $\varepsilon$. The government imposes tax $s(0 \leq s \leq 1)$ on carbon emissions generated by the manufacturers. The carbon tax for each product unit is $\varepsilon s$ and $\left(\varepsilon-w_{1}\right) s$ for no green innovation and radical green innovations, respectively. For clarity, the variables and notations used in this paper are listed as follows.

\subsection{Payoff Matrix}

Based on the assumptions above, the profit functions of manufacturer Group 1 and Group 2 are

$$
\begin{aligned}
& \pi_{i j}^{(1)}=\left(a+\theta w_{i}-\left(q_{1}+q_{2}\right)\right) q_{1}-c q_{1}-\frac{(1-r) k_{1} w_{i}^{2}}{2} \\
& \left.\pi_{i j}{ }^{2}\right)=\left(a+\theta w_{j}-\left(q_{1}+q_{2}\right)\right) q_{2}-c q_{2}-\frac{(1-r) k_{2} w_{j}^{2}}{2}
\end{aligned}
$$

where $i=1,2, j=1,2$. For example, $\pi_{11}(1)$ represents the profit of the manufacturer in Group 1 when both groups choose radical green innovation. Since both groups have a strategy set of radical innovation and incremental innovation, there are four possible strategy combinations.

a Both groups choose radical innovation

As both groups adopt radical innovation, it is reasonable to assume that the probability of the two companies taking the lead in radical innovation is equal. When the game equilibrium is reached, the optimal output and profit of the two manufacturer groups are as follows:

$$
\begin{gathered}
q_{1}{ }^{*}=\frac{\left(a+\theta w_{1}-c-\left(\varepsilon-w_{1}\right)\right)}{2}, q_{2}{ }^{*}=\frac{\left(a+\theta w_{1}-c-\left(\varepsilon-w_{1}\right)\right)}{4}, \\
\pi_{11}{ }^{(1)}=\frac{3\left(a+\theta w_{1}-c-s\left(\varepsilon-w_{1}\right)\right)^{2}}{32}-\frac{(1-r) k_{1} w_{1}{ }^{2}}{2}, \\
\pi_{11}{ }^{(2)}=\frac{3\left(a+\theta w_{1}-c-s\left(\varepsilon-w_{1}\right)\right)^{2}}{32}-\frac{(1-r) k_{2} w_{1}{ }^{2}}{2}
\end{gathered}
$$

For clarity, the proofs are detailed in Appendix A.

$b$ Group 1 chooses radical innovation; Group 2 chooses incremental innovation 
The optimal output and profit of the two manufacturer groups are as follows:

$$
\begin{gathered}
q_{1}^{*}=\frac{\left(a+2 \theta w_{1}-\theta w_{2}-c-2 s\left(\varepsilon-w_{1}\right)+s\left(\varepsilon-w_{2}\right)\right)}{2}, \\
q_{2}^{*}=\frac{\left(a+3 \theta w_{2}-2 \theta w_{1}-c-3 s\left(\varepsilon-w_{2}\right)+2 s\left(\varepsilon-w_{1}\right)\right)}{4}, \\
\pi_{12}{ }^{(1)}=\frac{\left(a+2 \theta w_{1}-\theta w_{2}-c+s\left(\varepsilon-w_{2}\right)-2 s\left(\varepsilon-w_{1}\right)\right)^{2}}{8}-\frac{(1-r) k_{1} w_{1}{ }^{2}}{2}, \\
\pi_{12}{ }^{(2)}=\frac{\left(a+3 \theta w_{2}-2 \theta w_{1}-c-3 s\left(\varepsilon-w_{2}\right)+2 s\left(\varepsilon-w_{1}\right)\right)^{2}}{16}-\frac{(1-r) k_{2} w_{2}^{2}}{2}
\end{gathered}
$$

The proofs are detailed in Appendix B.

c Group 1 chooses incremental innovation; Group 2 chooses radical innovation

The optimal output and profit of the two manufacturer groups are as follows:

$$
\begin{gathered}
q_{1}^{*}=\frac{a+3 \theta w_{2}-2 \theta w_{1}-c-3 s\left(\varepsilon-w_{2}\right)+2 s\left(\varepsilon-w_{1}\right)}{4}, \\
q_{2}^{*}=\frac{a+2 \theta w_{1}-\theta w_{2}-c-2 s\left(\varepsilon-w_{1}\right)+s\left(\varepsilon-w_{2}\right)}{2}, \\
\pi_{21}{ }^{(1)}=\frac{\left(a+3 \theta w_{2}-2 \theta w_{1}-c-3 s\left(\varepsilon-w_{2}\right)+2 s\left(\varepsilon-w_{1}\right)\right)^{2}}{16}-\frac{(1-r) k_{1} w_{2}{ }^{2}}{2}, \\
\pi_{21}{ }^{(2)}=\frac{\left(a+2 \theta w_{1}-\theta w_{2}-c-2 s\left(\varepsilon-w_{1}\right)+s\left(\varepsilon-w_{2}\right)\right)^{2}}{8}-\frac{(1-r) k_{2} w_{1}{ }^{2}}{2} .
\end{gathered}
$$

The proofs are detailed in Appendix C.

d Both groups choose incremental innovation

When the game equilibrium is reached, the optimal output and profit of the two manufacturer groups are as follows:

$$
\begin{gathered}
q_{1}^{*}=\frac{a+\theta w_{2}-c-s\left(\varepsilon-w_{2}\right)}{3}, q_{2}{ }^{*}=\frac{a+\theta w_{2}-c-s\left(\varepsilon-w_{2}\right)}{3}, \\
\pi_{22}{ }^{(1)}=\frac{\left(a+\theta w_{2}-c-s\left(\varepsilon-w_{2}\right)\right)^{2}}{9}-\frac{(1-r) k_{1} w_{2}^{2}}{2}, \\
\pi_{22}{ }^{(2)}=\frac{\left(a+\theta w_{2}-c-s\left(\varepsilon-w_{2}\right)\right)^{2}}{9}-\frac{(1-r) k_{2} w_{2}^{2}}{2} . \\
\pi_{22}{ }^{(2)}=\frac{\left(a+\theta w_{2}-c-s\left(\varepsilon-w_{2}\right)\right)^{2}}{9}-\frac{(1-r) k_{2} w_{2}^{2}}{2} .
\end{gathered}
$$

The proofs are detailed in Appendix D.

Based on the profit functions obtained above, we can have the following payoff matrix between the two groups in Table 1.

Table 1. Payoff matrix of the two manufacturer groups.

\begin{tabular}{cccc}
\hline & & \multicolumn{2}{c}{ Group 2 } \\
\cline { 2 - 4 } & & Radical Innovation $\boldsymbol{y}$ & Incremental Innovation 1 - $\boldsymbol{y}$ \\
\hline \multirow{2}{*}{ Group 1} & Radical Innovation $x$ & $\pi_{11}{ }^{(1)}, \pi_{11}{ }^{(2)}$ & $\pi_{12}{ }^{(1)}, \pi_{12}{ }^{(2)}$ \\
\cline { 2 - 4 } & Incremental Innovation $1-x$ & $\pi_{21}{ }^{(1)}, \pi_{21}{ }^{(2)}$ & $\pi_{22}{ }^{(1)}, \pi_{22}{ }^{(2)}$ \\
\hline
\end{tabular}




\subsection{Evolutionary Equilibrium Strategy Analysis}

Let the expected profit of the manufacturer in Group 1 be $X_{1}$ and $X_{2}$ when her choice is radical innovation and incremental innovation, respectively, and the average profit be $\bar{X}$. We therefore have

$$
\begin{gathered}
X_{1}=y \pi_{11}{ }^{(1)}+(1-y) \pi_{12}{ }^{(1)}, X_{2}=y \pi_{21}{ }^{(1)}+(1-y) \pi_{22}{ }^{(1)}, \\
\bar{X}=x X_{1}+(1-x) X_{2}
\end{gathered}
$$

Let the expected profit of the manufacturer in Group 2 be $Y_{1}$ and $Y_{2}$ when her choice is radical innovation and incremental innovation, respectively, and the average profit be $\bar{Y}$. We therefore have

$$
Y_{1}=x \pi_{11}^{(2)}+(1-x) \pi_{21}^{(2)}, Y_{2}=x \pi_{12}^{(2)}+(1-x) \pi_{22}{ }^{(2)}, \bar{Y}=y Y_{1}+(1-y) Y_{2}
$$

After applying replicator dynamic analysis for the manufacturer Groups 1 and 2 [51], we can obtain the replicator dynamic equation as below:

$$
\begin{aligned}
& F(x)=\frac{d x}{d t}=x\left(X_{1}-\bar{X}\right)=x(1-x)\left(X_{1}-X_{2}\right)= \\
& x(1-x)\left[y\left(\pi_{11}(1)-\pi_{21}(1)\right)+(1-y)\left(\pi_{12}{ }^{(1)}-\pi_{22}{ }^{(1)}\right)\right] \\
& F(y)=\frac{d y}{d t}=y\left(Y_{1}-\bar{Y}\right)=y(1-y)\left(Y_{1}-Y_{2}\right)= \\
& y(1-y)\left[x\left(\pi_{11}{ }^{(2)}-\pi_{12}{ }^{(2)}\right)+(1-x)\left(\pi_{21}{ }^{(2)}-\pi_{22}{ }^{(2)}\right)\right]
\end{aligned}
$$

In order to analyze the stable strategy in Equation (11), we need to obtain the critical value first. To this end, first, let $F(x)=0$ and we can get $x^{*}=0$ or $x^{*}=1$, and $y^{*}=\frac{\pi_{12}(1)-\pi_{22}(1)}{\left(\pi_{12}{ }^{(1)}-\pi_{22}{ }^{(1)}\right)-\left(\pi_{11}{ }^{(1)}-\pi_{21}{ }^{(1)}\right)}$. When $y^{*}=\frac{\pi_{12}^{(1)}-\pi_{22}(1)}{\left(\pi_{12}{ }^{(1)}-\pi_{22}{ }^{(1)}\right)-\left(\pi_{11}{ }^{(1)}-\pi_{21}{ }^{(1)}\right)}, F(x)$ is always equal to 0 . In other words, each $x$ is a stable point. Next, we conduct the equilibrium analysis of Group 2. To this end, first, let $F(x)=0$ and we can get $y^{*}=0$ or $y^{*}=1$, and $x^{*}=\frac{\pi_{21}{ }^{(2)}-\pi_{22}{ }^{(2)}}{\left(\pi_{21}{ }^{(2)}-\pi_{22}{ }^{(2)}\right)-\left(\pi_{11}{ }^{(2)}-\pi_{12}{ }^{(2)}\right)} . F(x)$ is always equal to 0 . In other words, each $y$ is a stable point.

Based on the stable strategies of two groups analyzed so far, we obtain five dynamic system equilibrium points $(1,1),(0,0),(0,1),(1,0)$, and $\left(x^{*}, y^{*}\right)$, where $\left(x^{*}, y^{*}\right)$ is the saddle point, as follows:

$$
x^{*}=\frac{\pi_{21}^{(2)}-\pi_{22}^{(2)}}{\left(\pi_{21}{ }^{(2)}-\pi_{22}{ }^{(2)}\right)-\left(\pi_{11}(2)-\pi_{12}(2)\right)}, y^{*}=\frac{\pi_{12}{ }^{(1)}-\pi_{22}{ }^{(1)}}{\left(\pi_{12}{ }^{(1)}-\pi_{22}{ }^{(1)}\right)-\left(\pi_{11}(1)-\pi_{21}(1)\right)}
$$

Next, to study the stability of the equilibrium points, we construct the Jacobian matrix of Equations (11) and (12) as follows:

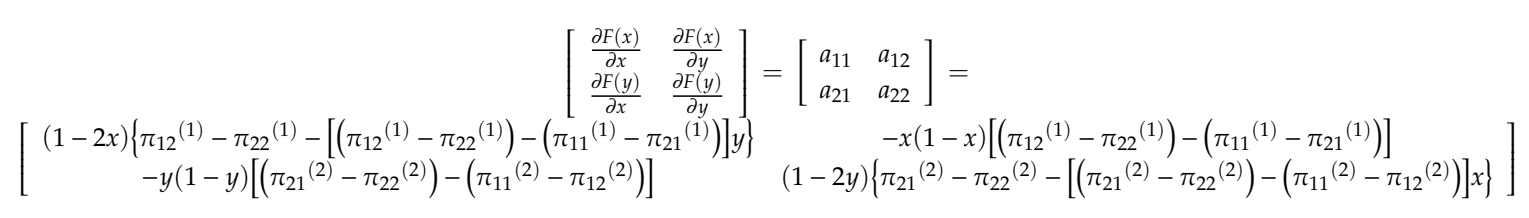

According to the local stability determination rule [52], when the two conditions of $\operatorname{det} J=a_{11} a_{22}-$ $a_{12} a_{21}>0$ and $t r J=a_{11}+a_{22}<0$ are satisfied, the equilibrium point is an Evolutionary Stable Strategy (ESS) [53]. After performing a stability analysis on each equilibrium point, we get the following three propositions as follows:

Proposition 1. When the following conditions are satisfied:

$$
\begin{aligned}
& \frac{\left[3\left(a+\theta w_{1}-c-s\left(\varepsilon-w_{1}\right)\right)^{2}-2\left(a+3 \theta w_{2}-2 \theta w_{1}-c-s \varepsilon+s\left(3 w_{2}-2 w_{1}\right)\right)^{2}\right]}{32}>\frac{(1-r) k_{2}\left(w_{1}^{2}-w_{2}^{2}\right)}{2}>\frac{(1-r) k_{1}\left(w_{1}^{2}-w_{2}^{2}\right)}{2} \\
& >\frac{9\left(a+2 \theta w_{1}-\theta w_{2}-c+s\left(\varepsilon-w_{2}\right)-2 s\left(\varepsilon-w_{1}\right)\right)^{2}-8\left(a+\theta w_{2}-c-s\left(\varepsilon-w_{2}\right)\right)^{2}}{72}
\end{aligned}
$$


the two enterprise groups in the system converge to one of the two evolutionary stable strategies: \{radical innovation, radical innovation\} and \{incremental innovation, incremental innovation\}.

Proposition 1 suggests that whatever the initial strategy of the two groups, the strategies of \{radical innovation, incremental innovation\} and \{incremental innovation, radical innovation\} are unstable. In this case, the probability of the two groups choosing the two stable strategies depends on the saddle point $\left(x^{*}, y^{*}\right)$. The probabilities of converging to \{radical innovation, radical innovation\} decrease in the value of $\left(x^{*}, y^{*}\right)$, which is determined by the carbon tax rate, innovation subsidy level, consumer green preference coefficient, and innovative cost coefficient. Proposition 1 also suggests that the above factors are effective in influencing the modes choice of enterprises green innovation. The enterprises with innovation capability advantages are more likely to choose radical innovation compared with enterprises with innovation capability disadvantages as the two groups are facing the same environment.

Proposition 2. When the following conditions are satisfied:

$$
\begin{aligned}
& \frac{(1-r) k_{2}\left(w_{1}{ }^{2}-w_{2}{ }^{2}\right)}{2}>\frac{(1-r) k_{1}\left(w_{1}{ }^{2}-w_{2}{ }^{2}\right)}{2}>\frac{\left[3\left(a+\theta w_{1}-c-s\left(\varepsilon-w_{1}\right)\right)^{2}-2\left(a+3 \theta w_{2}-2 \theta w_{1}-c-s \varepsilon+s\left(3 w_{2}-2 w_{1}\right)\right)^{2}\right]}{32}, \\
& \frac{(1-r) k_{2}\left(w_{1}{ }^{2}-w_{2}{ }^{2}\right)}{2}>\frac{(1-r) k_{1}\left(w_{1}{ }^{2}-w_{2}{ }^{2}\right)}{2}>\frac{9\left(a+2 \theta w_{1}-\theta w_{2}-c+s\left(\varepsilon-w_{2}\right)-2 s\left(\varepsilon-w_{1}\right)\right)^{2}-8\left(a+\theta w_{2}-c-s\left(\varepsilon-w_{2}\right)\right)^{2}}{72}
\end{aligned}
$$

the two enterprise groups in the system converge to the evolutionary stable strategy of \{incremental innovation, incremental innovation\}.

Proposition 2 implies that the stable strategy of \{incremental innovation, incremental innovation\} is the only ESS of system, \{incremental innovation, radical innovation\} and \{radical innovation, incremental innovation\} are unstable, and \{radical innovation, radical innovation\} is unstable as well. It suggests that incremental innovation will be the equilibrium regardless the initial strategies. In this case, the increased profit from radical innovation is too small to cover the innovation investment, which is choosing radical innovation will hurt the enterprise's profit, nor can subsidies make up for the increase in costs caused by radical innovation. Radical innovation has large technical and economic barriers, and after a continuous game, the enterprises will eventually choose incremental innovation. The government may need to create a good environment for radical innovation in other areas, such as formulating preferential policies for technology introduction and accelerating the cultivation of innovative talents.

Proposition 3. When the following conditions are satisfied:

$$
\begin{aligned}
& \frac{\left[3\left(a+\theta w_{1}-c-s\left(\varepsilon-w_{1}\right)\right)^{2}-2\left(a+3 \theta w_{2}-2 \theta w_{1}-c-s \varepsilon+s\left(3 w_{2}-2 w_{1}\right)\right)^{2}\right]}{32}>\frac{(1-r) k_{2}\left(w_{1}{ }^{2}-w_{2}{ }^{2}\right)}{2} \\
& >\frac{(1-r) k_{1}\left(w_{1}{ }^{2}-w_{2}{ }^{2}\right)}{2} \\
& \frac{9\left(a+2 \theta w_{1}-\theta w_{2}-c+s\left(\varepsilon-w_{2}\right)-2 s\left(\varepsilon-w_{1}\right)\right)^{2}-8\left(a+\theta w_{2}-c-s\left(\varepsilon-w_{2}\right)\right)^{2}}{72}>\frac{(1-r) k_{2}\left(w_{1}{ }^{2}-w_{2}{ }^{2}\right)}{2}>\frac{(1-r) k_{1}\left(w_{1}{ }^{2}-w_{2}{ }^{2}\right)}{2}
\end{aligned}
$$

the two enterprise groups in the system converge to the evolutionary stable strategy of \{radical innovation, radical innovation\}.

Proposition 3 suggests that, under the carbon tax and the peer competition, the enterprise would choose radical innovation to meet the demand of green consumers, so the innovation subsidy and the extra profit obtained from the market could cover the innovation investment. As a result, a good green innovation environment will form in the market. Proposition 3 also implies that the minimum additional net profit for enterprises choosing radical innovation is positive in this case. In other words, the enterprise will choose radical innovation only when the additional profit it gains from radical innovation are greater than the cost savings from incremental innovation. 


\section{Simulations and Results}

\subsection{The Evolution Path}

Our theoretical results in Section 3 show that there are three stable strategies in the system, as stated in the three propositions above, respectively. Our findings also indicate that factors such as carbon tax rate, innovation subsidy level, and consumers' green preference are important to the enterprise's green innovation mode selection. To illustrate our analytic results, we now conduct simulative examples to illustrate the evolution paths of the system. Furthermore, we conduct sensitivity analysis to illustrate how various parameters affect the evolution.

Specifically, we employ MatlabR2014a as the simulation software. Following Xu et al. (2017), we set the initial parameters as in Table 2.

Table 2. Parameter initial value.

\begin{tabular}{ccccccc}
\hline Parameters & $\boldsymbol{a}$ & $\boldsymbol{c}$ & $\boldsymbol{\varepsilon}$ & $\boldsymbol{w}_{\mathbf{1}}$ & $\boldsymbol{w}_{\mathbf{2}}$ & $\boldsymbol{\Delta} \boldsymbol{k}$ \\
\hline Value & 100 & 50 & 12 & 1.4 & 0.2 & 11 \\
\hline
\end{tabular}

Setting the parameters to satisfy the conditions of the three propositions in Section 3, we can obtain the evolution paths of the system, which are depicted in Figures $1-3$, where the $x$-axis represents Group 1 's probability of choosing radical innovation, while the $y$-axis represents Group 2's probability of choosing radical innovation.

\subsubsection{Scenario 1}

We set the parameters as: $\theta=0.5, r=0.2, s=0.3$, and $k_{2}=15$, which satisfy the conditions required in Proposition 1. The evolution path of the system is shown in Figure 1a. It can be seen from Figure 1a that there are two stable strategies in the system, consistent with Proposition 1 . That is, the system converges to $(1,1)$ and $(0,0)$ regardless of the initial strategies, that is the stable strategies of \{radical innovation, radical innovation\} and \{incremental innovation, incremental innovation\} simultaneously exist. The point $\mathrm{E}$ in the Figure $1 \mathrm{a}$ is the saddle point obtained in the previous section. The area of the region ABDE represents the probability of the enterprise groups in the system converging to progressive innovation. Keeping other parameters unchanged and varying, $k_{2}$, we can see how the innovative cost coefficient affects the evolution path.

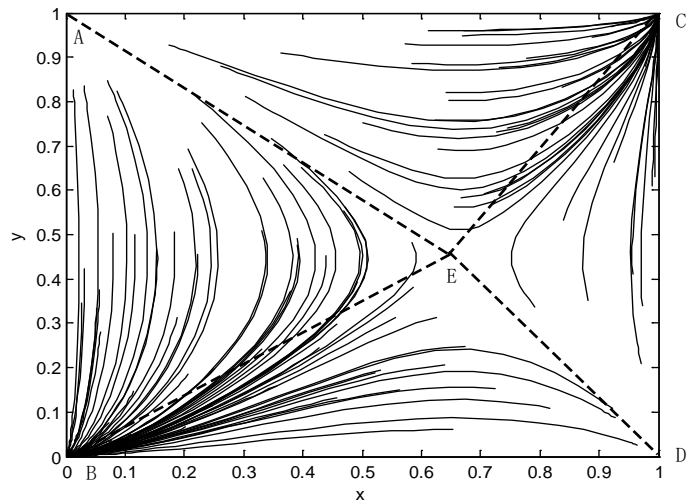

(a)

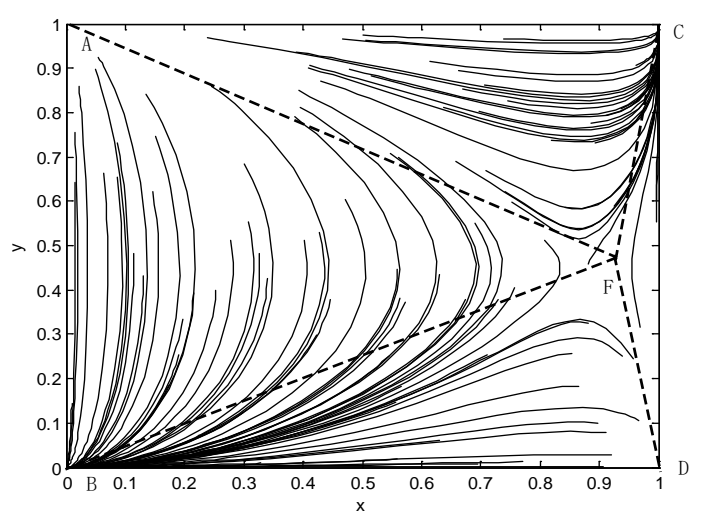

(b)

Figure 1. The evolution path of the system when both $(1,1)$ and $(0,0)$ are ESS (Evolutionary Stable Strategy): (a) The evolution path when $k_{2}=15$; (b) the evolution path when $k_{2}=25$.

We then set $k_{2}=25$, and the corresponding evolution path is shown in Figure $1 \mathrm{~b}$, where point $\mathrm{F}$ is the new saddle point of the system with the innovation cost coefficient increases to 25 . We can 
see from Figure $1 b$ that the area of the regional ABDF increases with the increase of the innovation cost coefficient, which means that the probability of the system's evolution to incremental innovation becomes greater. In other words, the more capable manufacturer would choose radical innovation in a higher probability and a faster convergence speed. It is also proved that, in this case of Proposition 1 , the cost coefficient is a key factor to influence the choice of the enterprise.

\subsubsection{Scenario 2}

In scenario 2, we set the parameters as: $\theta=0.1, r=0.2, s=0.5, k_{2}=27$, which satisfy the conditions required for Proposition 2. The evolution path is shown in Figure 2, which is consistent with Proposition 2. In this case, there is only one stable strategy. That is, the system converges to $(0,0)$ no matter what the initial strategies are adopted by the two groups. It implies that enterprises choose to carry out radical innovation will reduce profits; government subsidies cannot make up the huge investment cost. After participating in long-term repeated games in the system, the proportion of enterprises that choose radical innovation gradually decreases until all of them choose to make incremental innovation and to pay more carbon taxes. The ESS profile thus becomes incremental innovation, incremental innovation\}.

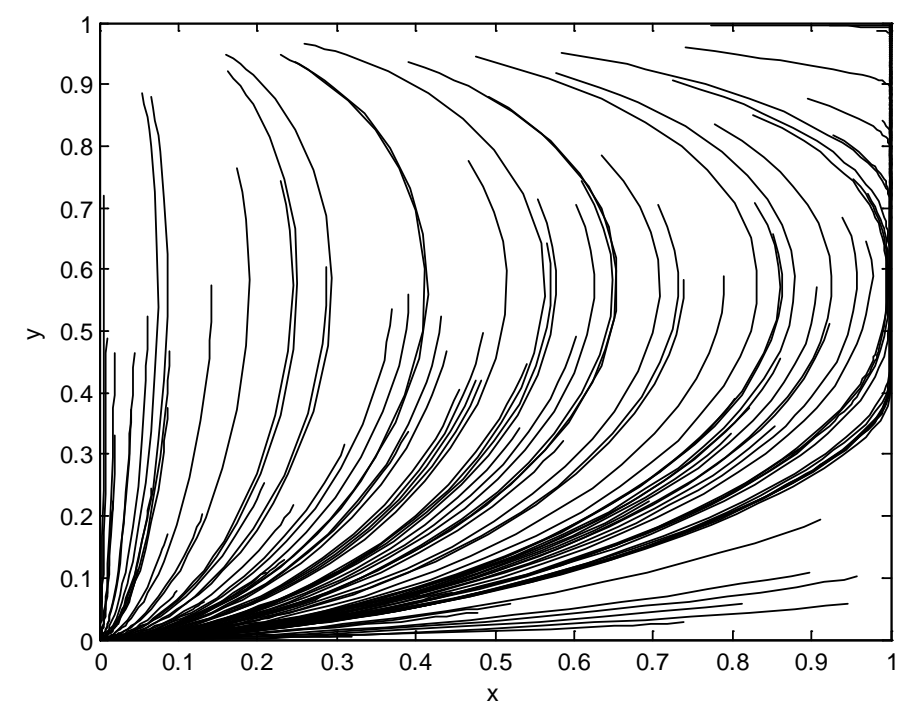

Figure 2. The evolution path of system when only $(0,0)$ is ESS.

\subsubsection{Scenario 3}

In this scenario, we increase the coefficient of consumer's green preference to 0.9 and reduce the carbon tax rate to 0.1 while keeping other parameters unchanged. These parameters satisfy the conditions required in Proposition 3. The corresponding evolution path is shown in Figure 3. It can be seen that there is only one stable strategy. That is, the system converges to $(1,1)$ no matter what initial strategies are adopted by the two groups. The level of consumer preference has reached a very high level. We could believe that the market has great demand for green products, bringing new business opportunities and potential profits for enterprises, and stimulating them to choose radical innovations that can produce greener products to meet market preferences. We also find that even the carbon tax is low in this case, and enterprises still choose to take radical innovation, which means that compared with the cost of innovation and carbon tax burden, enterprises care more about the potential market share. After several repeated games, the proportion of enterprises choosing to make radical innovation continues to increase until all of them choose radical innovation, at which point the ideal state of green innovation evolution has been reached. The ESS profile is \{radical innovation, radical innovation\}. 


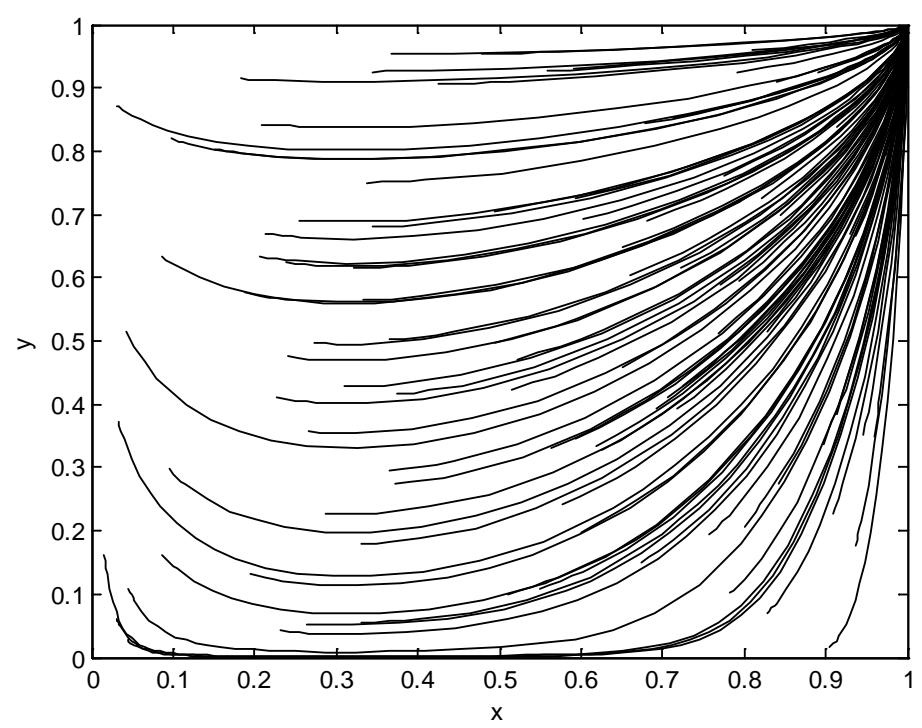

Figure 3. The evolution path of system when only $(1,1)$ is ESS.

\subsection{Sensitivity Analysis}

We keep the initial parameters the same as those in Section 4.1.1 to satisfy the conditions needed in Proposition 1. In other words, we focus on the effect of various parameters on the evolution path and convergence speed when there are two stable strategies in the system, that is the two manufacturer groups of the evolution system may choose the \{radical innovation, radical innovation\} strategy or the \{incremental innovation, incremental innovation\} strategy, which stable state the system will converge to depends on changes in the external environment (including policy, market and peer competition) and the enterprise's own innovation ability. In the next sections (4.2.1-4.2.3), we will simulate a change in the external environment by changing a certain parameter so as to analyze the influence mechanism of this factor on the choice of enterprise's green innovation mode.

\subsubsection{The Subsidy Coefficient and Initial Strategies}

We now shift our focus to government subsidy. We set the parameters as $\theta=0.1, s=0.3, k_{2}=15$ and let the innovation subsidy level from the government be 0.2 and 0.4 to depict the evolution path of the manufacturers. Let $y_{0}=0.7$; that is, we obtain the evolution path of the manufacturer Group 1 when $70 \%$ of Group 2 adopts the radical innovation, which is shown in Figure 4 . Let $y_{0}=0.5$, and we get the evolution path of Group 1 when $50 \%$ of Group 2 adopts the radical innovation, which is shown in Figure 5. Comparing Figures 4 and 5, we obtain the following observation.

- Observation 1: When there are two stable strategies in the system, a higher innovation subsidy will lead to a higher probability that the manufacturer of Group 1 will adopt radical innovation as well as a higher convergence speed, which means in this period, the incentive effect of subsidy is obvious. The initial strategy of both groups can influence the evolution path. A higher initial proportion of choosing radical innovation leads to a higher probability that manufacturers choose radical innovation as well as a higher convergence speed, which means that the decision of competitors lead the pressure to push the enterprise chooses radical innovation to keep and expand the market share. 


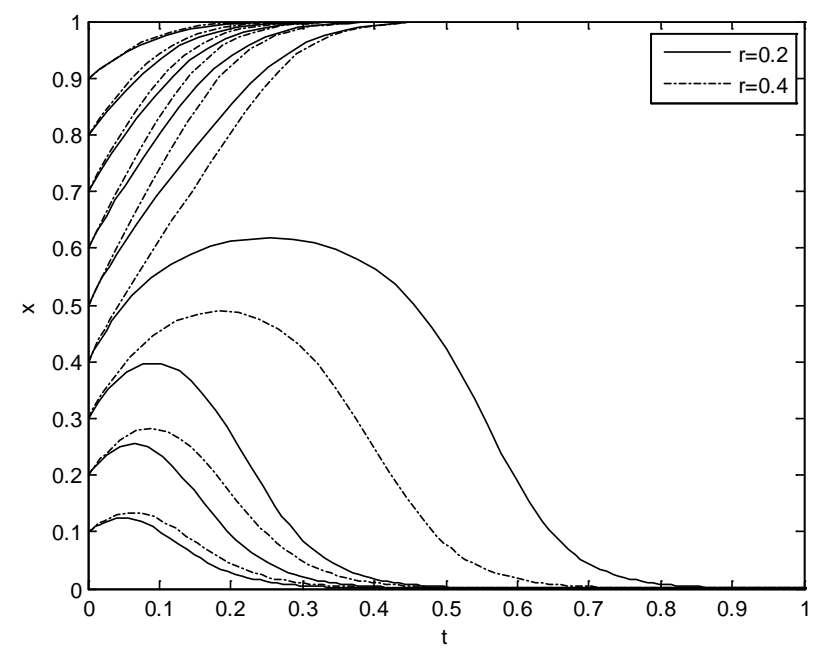

Figure 4. The impact of $r$ on Group 1 when $y_{0}=0.7$.

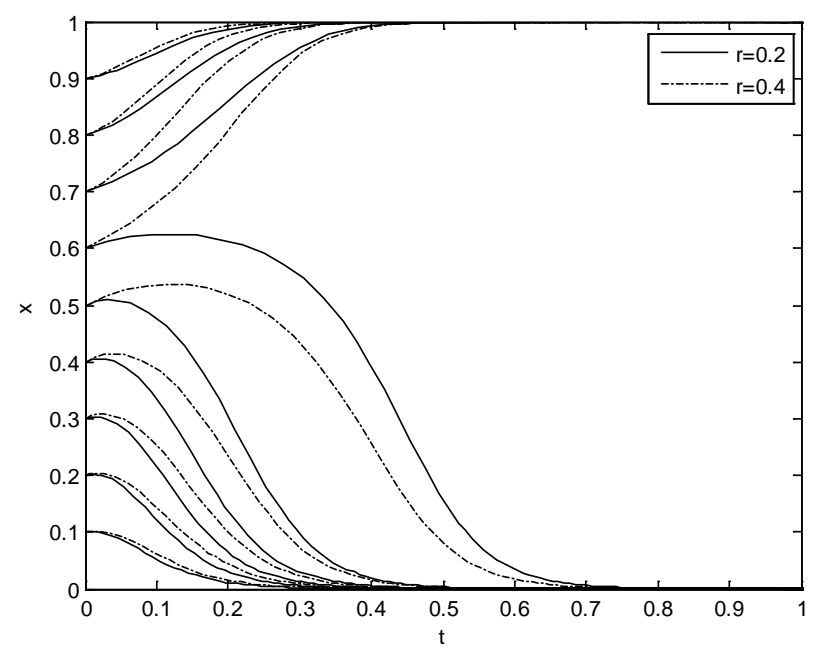

Figure 5. The impact of $r$ on Group 1 when $y_{0}=0.5$.

\subsubsection{Carbon Tax Rate and Initial Strategies}

We set the parameters as $\theta=0.5, r=0.3, k_{2}=15$, and let the carbon tax rate be 0.2 and 0.4 to analyze the evolution path of manufacturers under different carbon tax rates. Let $y_{0}=0.7$, and we get the evolution path of manufacturer Group 1 when $70 \%$ of Group 2 will take the radical innovation which is shown in Figure 6. Let $y_{0}=0.5$, and we get the evolution path of Group 1 when $50 \%$ of Group 2 will take the radical innovation which is shown in Figure 7. Comparing Figures 6 and 7, we have the following observation.

- Observation 2: When there are two stable strategies in the system, the carbon tax could incentivize the manufacturers to choose radical innovation under appropriate conditions of the initial strategy. When carbon tax can positively motivate companies to adopt radical innovations, the higher the tax rate, the slower the convergence speed of manufacturers is. The initial strategy also affects the effect of carbon tax rates on the evolution path of the manufacturers. The higher the initial proportions of both groups are, the more salient the incentive effects of carbon tax on the manufacturer's radical innovation selection. However, higher carbon tax rate does not always help radical green innovation. When the initial proportion of the manufacturers choosing radical innovation is low, the market environment is not conducive to radical innovation. In this case, even if the carbon tax rate is relatively high, the manufacturer will still choose incremental innovation. 


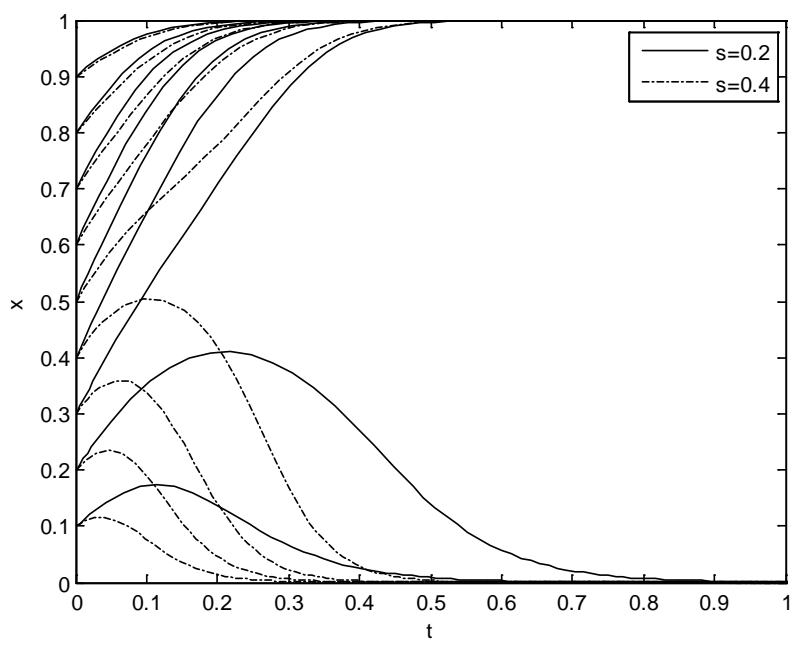

Figure 6. The impact of $s$ on Group 1 when $y_{0}=0.7$.

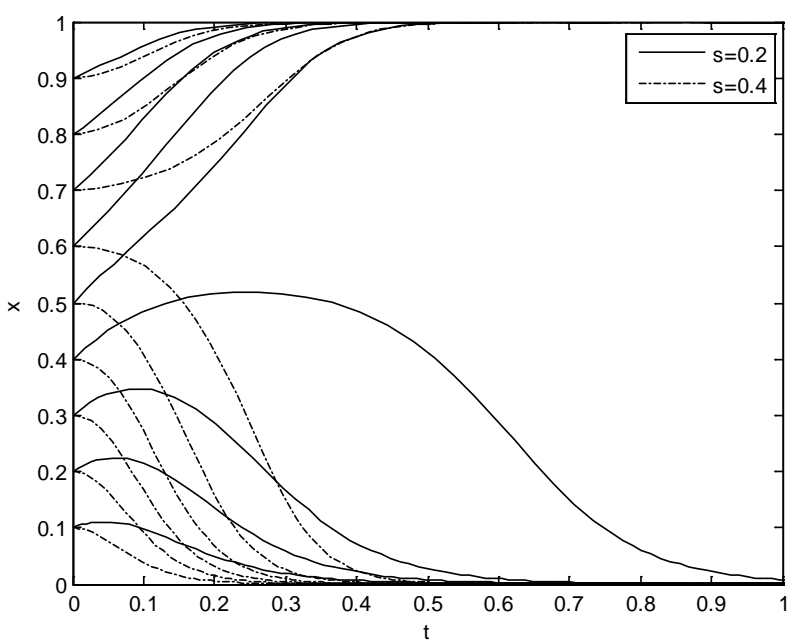

Figure 7. The impact of $s$ on Group 1when $y_{0}=0.5$.

\subsubsection{Effect of the Level of Consumer Green Preference and Initial Strategy}

We set the parameters as $r=0.2, s=0.3, k_{2}=15$, and let the level of consumer green preferences be 0.3 and 0.7 to analyze the evolution path of the manufacturers under different levels of consumer green preference. Let $y_{0}=0.7$, and we get the evolution path of manufacturer Group 1 when $70 \%$ of Group 2 will take the radical innovation which is shown in Figure 8. Let $y_{0}=0.5$, and we get the evolution path of Group 1 when $50 \%$ of Group 2 will take the radical innovation, which is shown in Figure 9. The comparison of Figures 8 and 9 leads to the following observation.

- Observation 3: When there are two stable strategies in the system, the higher the level of consumer green preference is, which bringing new markets and opportunities to enterprises, the higher the probability manufacturer of Group 1 will take radical innovation is, and the faster the convergence speed is. However, these positive relationships depend on the manufacturer's green innovation capability and the initial proportion of the manufacturers choosing radical innovation. The initial strategy of both groups can influence the evolution path, the higher the initial proportions of choosing radical innovation, the more obvious of the positive influence of the consumer green preference on the manufacturer's choice for radical innovation. The competition among peers makes consumer preferences have a more significant impact on enterprise green decisions, which is also in line with reality. 


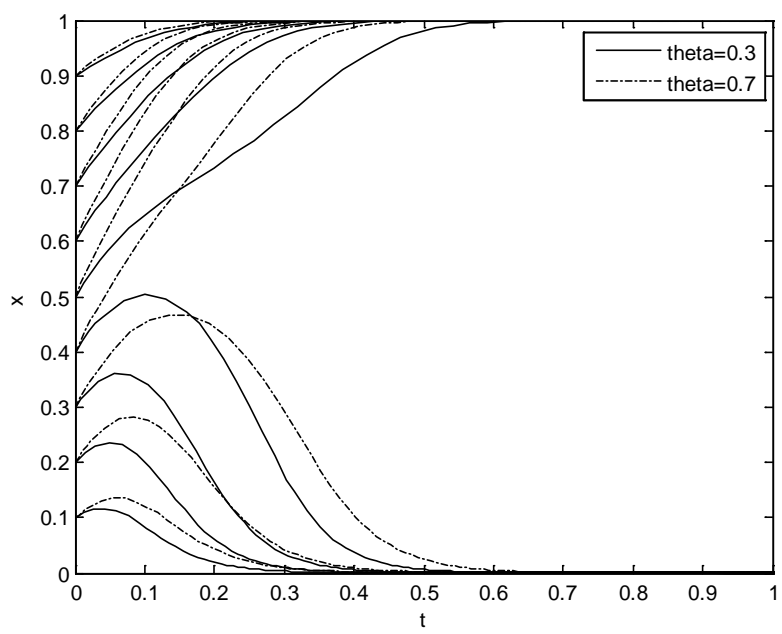

Figure 8. The impact of $\theta$ on Group 1 when $y_{0}=0.7$.

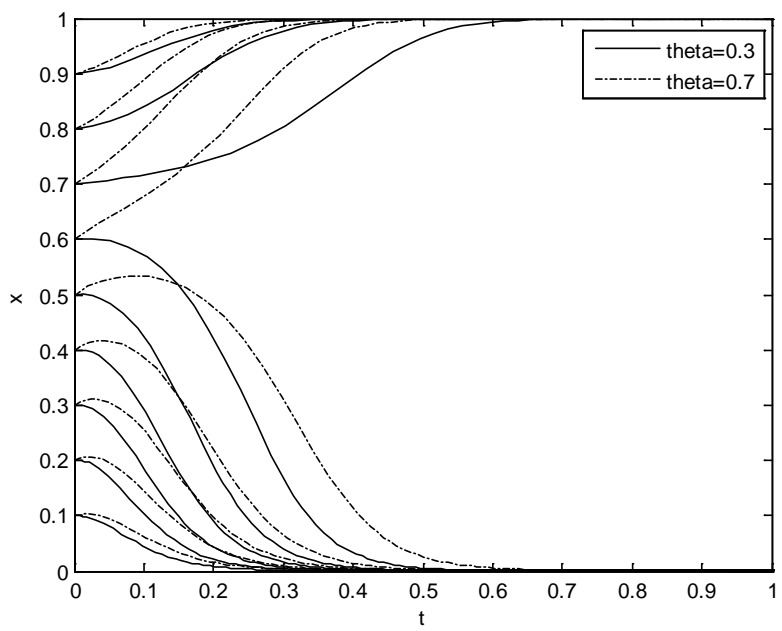

Figure 9. The impact of $\theta$ on Group 1 when $y_{0}=0.5$.

\subsection{Analysis of the Withdrawal Conditions of the Innovation Subsidy}

We set the parameters as $\theta=0.7, s=0.2$, and $y_{0}=0.7$ and regard the carbon tax is the existing regulation. We let the subsidy levels be 0 and 0.4 and keep the other parameters the same as those in Section 4.1.1. This is to compare and analyze the incentive effects of joint policies and the single carbon tax policy on the manufacturers' radical green innovation choice and identify the conditions under which the government innovation subsidy can be withdrawn. Enterprise green innovation cannot always rely on government guidance. One very prominent reason is the constraint of government fiscal budgets. Therefore, we need to discuss the conditions under which government subsidies can be withdrawn without affecting the innovation of enterprises. Because the model construction is too complicated, it is difficult to obtain mathematical proof by derivation, and only preliminary analysis can be performed through numerical simulation.

Figure 10 depicts the impact of subsidy level on the evolution path. From Figure 10, we can see when the initial proportion of choosing radical innovation is small, the impact of subsidy level on the manufacturers' choices of green innovation modes is pronounced. For example, when $x_{0}=0.2$, which means that the industry's green innovation is still at an early stage. In this case, when there is innovation subsidy from the government, the manufacturers are evolving toward radical innovation. When there is no subsidy, they are evolving toward incremental innovation. When $x_{0} \geq 0.6$, which means that green innovation practice in the industry is in the middle and late stages, the impacts of innovation subsidies on the trend and speed of manufacturer evolution become less pronounced. 
- Observation 4: When the initial proportion of manufacturers choosing radical innovation is low, that is the industry or the market by itself cannot promote radical innovation, the reasons may rely on the low market acceptance or large barriers to technological innovation, the incentive effect of innovation subsidy is particularly salient. Compared with the use of carbon tax alone, the joint use of carbon tax and innovation subsidy is superior to encourage the manufacturers to choose radical innovation. In other words, this proves the important role of government innovation subsidy in the early stage of green innovation in the industry. (Here, we use the proportion of enterprises that choose radical innovation to represent the overall innovation process.) As the level of consumers' green preference and the proportion of manufacturers choose radical innovation increase, the impacts of innovation subsidy on the manufacturer's choices of radical innovation and convergence speed become less significant. This is because increasing market green preferences can reduce the risks caused by the uncertainty of demand and stimulate enterprises to produce greener products to grab more market share. When the additional profits from the market are sufficient to make up for the costs of radical innovation, government subsidies no longer have a significant effect on enterprises. In this case, carbon tax, consumer green preference, and market competition could drive the manufacturer to adopt radical innovation. In other words, the government can withdraw innovation subsidy without hurting green innovation adoption.

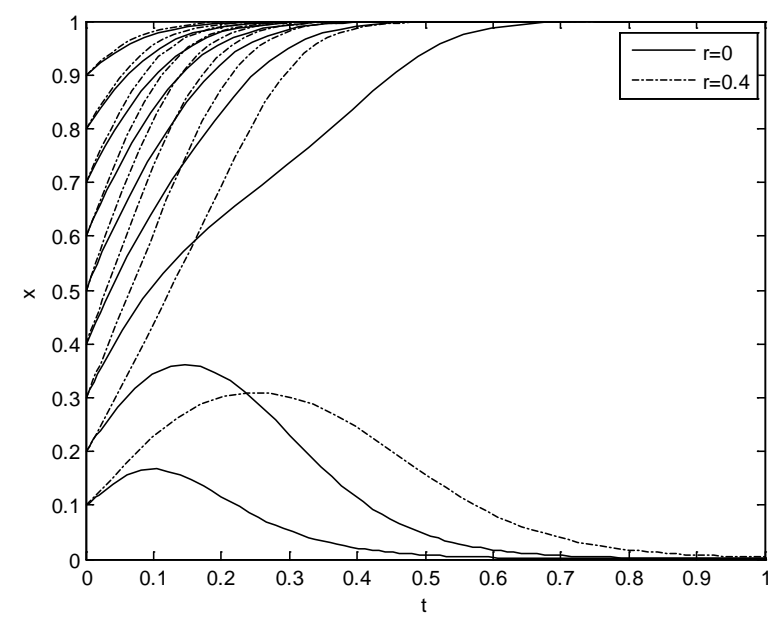

Figure 10. The impact of subsidy level on the evolution path.

\section{Conclusions and Discussions}

In many manufacturing industries, green innovation has become increasingly critical to drive sustainable development. Yet, the question of how the adoption of green innovation is influenced and evolved has been inadequately answered. In this study, we contribute to the literature by addressing this question. Specifically, we construct a two-population evolutionary game model where we consider consumer green preference, the capability of enterprise absorbing and adopting technology, market competition, and the joint policies of carbon taxes and innovation subsidies. We then analyze the dynamic process of the manufacturers' choices of green innovation. We focus on the conditions when the system reaches the stable point. In this way, we can identify the factors that affect the probability of enterprises choosing radical innovation. Furthermore, we conduct numerical simulation to confirm our theoretical results and analyze how different factors affect the evolution path.

Our main results are as follow. First, we prove there are three possible stable strategies in the system: the system will either converge to \{incremental innovation, incremental innovation\}, or \{radical innovation, radical innovation\}, or alternatively, the two stable strategies co-exist, we identify their corresponding required conditions. Nevertheless, only when the minimum additional net profit obtained by enterprises through radical green innovation is positive, the enterprise group will evolve to 
the "ideal state" of choosing a radical green innovation mode. Second, we demonstrate that carbon tax, innovation subsidy, consumer green preference, and manufacturers' absorptive and adoption capability can improve the possibility of enterprise's radical green innovation activities and can accelerate the evolution. We show the superiority of the joint policies of carbon tax and innovation subsidy in promoting radical green innovation and environmental enhancement. We also identify the important incentive role of innovation subsidy in the early stage of green innovation in the industry. We also discuss the conditions when government innovation subsidy can be withdrawn.

We then conduct numerical analysis to specifically analyze how the above factors affect the evolution path of the enterprise's choice of green innovation modes and discuss under which conditions the impact is most significant. These simulative analyses strongly support and further clarify our theoretical findings.

Based on the results above, we propose the following insights for the government when formulating policies on promoting radical green innovation and achieving emission reduction goals. First, the government could strengthen environmental publicity or subsidized green products to raise consumers' environmental awareness and cultivate their green consumption habits. By doing so, manufacturers are incentivized to carry out radical green innovation. Market demand preferences will stimulate companies to green production to increase market share. Second, the government can introduce preferential policies through the formulation of technology and jointly cultivate innovative talents with scientific research institutions of colleges and universities to enhance the innovation ability of enterprises, which will help reduce the cost of innovation and the risk of failure of innovation. Third, the government can keep abreast of the proportion of the manufacturers that implement radical green innovation in the industry and adjust the policies according to the different stages of green innovation in the industry. Finally, the government should facilitate the protection of intellectual property of green innovation and prevent the negative impact of knowledge spillover effects among manufacturers.

There are several limitations in this paper, which also open doors to future research. First, the model we construct can only simulate the objective environment as much as possible, but considering the feasibility of model derivation, some factors have not been covered in the model. For example, to simplify our model, we assume that the consumer green preference as constant and that innovation do not affect the unit product cost. In reality, the consumers are heterogeneous, which influences the market demand and the expected profit of enterprise. Second, there is no empirical support to validate the theoretical predictions. Third, we ignore the government's fiscal constraints in formulating environmental policies.

Along the findings proposed in this paper, there are several aspects that can be pursued as future research. First, parallel research on the maximization of social welfare and consumer surplus can be conducted to generate different policy implications. We expect the results will be different from those under the sole objective of emission reduction. Second, a project that extends current model setting by incorporating government and consumers to construct a three-population evolutionary game model is worth investigation. Third, the propositions in this theory paper can be converted to hypotheses, and empirical verification can be conducted by collecting data on emission reduction and policy implementation. Hence, the theoretical predictions made in this paper can be verified in a realistic manner. Finally, we can extend our study to the contexts of supply chains, especially those for services and innovation.

Author Contributions: Conceptualization: S.Z.; formal analysis: Y.Y. and Q.Z.; Resources, project administration: S.Z.; Methodology, writing —original draft preparation: C.M.Q. and Y.Y.; software, validation: A.T.; Manuscript Revision: C.M.Q. and Y.Y. All authors have read and agreed to the published version of the manuscript.

Funding: This research is partly supported by SSHRC Insight Grant 435-2016-0250 and research grant from Lazaridis Institute.

Acknowledgments: We thank the anonymous reviewers for their advice, which greatly contributes to the improvement of the article.

Conflicts of Interest: The authors declare no conflict of interest. 


\section{Abbreviations}

a Market size

c Unit production cost

$s \quad$ Carbon tax rate

$p \quad$ Unit selling price

$Q \quad$ The total quantity of the products sold in the market

$r \quad$ Government innovation subsidy level

$\theta \quad$ Consumer green preference coefficient

$\varepsilon \quad$ The initial carbon emission per product before green innovation

$w_{1} \quad$ Unit product emission reduction due to radical innovation

$w_{2} \quad$ Unit product emission reduction due to incremental innovation

$k_{1}, k_{2} \quad$ Innovative cost coefficient of manufacturer Group 1 and Group 2, respectively

$\Delta k \quad$ The difference between the two groups' innovation cost coefficient

$q_{1}, I_{2} \quad$ The output of manufacturer in Group 1 and Group 2, respectively

$x, y \quad$ The proportion of the manufacturer that chooses radical innovation among the manufacturer Group 1 and Group 2, respectively, which are the function of time $t$

$x_{0}, y_{0} \quad$ The initial proportion of the manufacturer that chooses radical innovation among the manufacturer Group 1 and Group 2, respectively

\section{Appendix A}

First, we assume that Group 1 first chooses radical innovation, and then Group 2 follow to choose radical innovation. We have the profit function of the manufacturers in the two groups as follows:

$$
\begin{aligned}
& \pi_{11}^{(1)}=\left(a+\theta w_{1}-\left(q_{1}+q_{2}\right)\right) q_{1}-c q_{1}-s\left(\varepsilon-w_{1}\right) q_{1}-\frac{(1-r) k_{1} w_{1}^{2}}{2} \\
& \pi_{11}{ }^{(2)}=\left(a+\theta w_{1}-\left(q_{1}+q_{2}\right)\right) q_{2}-c q_{2}-s\left(\varepsilon-w_{1}\right) q_{2}-\frac{(1-r) k_{2} w_{1}^{2}}{2}
\end{aligned}
$$

As the manufacturer in group 1 is the Stackelberg game leader, we first obtain the partial derivative of $q_{2}$ for $\pi_{11}{ }^{(2)}$ :

$$
\frac{\partial \pi_{11}(2)}{\partial q_{2}}=a+\theta w_{1}-q_{1}-2 q_{2}-c-s\left(\varepsilon-w_{1}\right)
$$

Let $\frac{\partial \pi_{11}(2)}{\partial q_{2}}=0$, and we can get $q_{2}=\frac{\left(a+\theta w_{1}-q_{1}-c-\left(\varepsilon-w_{1}\right)\right)}{2}$. Substituting this into the expression $\pi_{11}(1)$, we obtain

$$
\pi_{12}{ }^{(1)}=\left(\frac{a+2 \theta w_{1}-\theta w_{2}-q_{1}+c+s\left(\varepsilon-w_{2}\right)}{2}\right) q_{1}-c q_{1}-s\left(\varepsilon-w_{1}\right) q_{1}-\frac{(1-r) k_{1} w_{1}^{2}}{2}
$$

Then we obtain the partial derivative of $q_{1}$ for $\pi_{11}{ }^{(1)}$ :

$$
\frac{\partial \pi_{11}(1)}{\partial q_{1}}=\frac{\left(a+\theta w_{1}+c+s\left(\varepsilon-w_{1}\right)-2 c-2 s\left(\varepsilon-w_{1}\right)\right)}{2}-q_{1}
$$

Let $\frac{\partial \pi_{11}(1)}{\partial q_{1}}=0$, and we can obtain $q_{1}^{*}=\frac{\left(a+\theta w_{1}-c-s\left(\varepsilon-w_{1}\right)\right)}{2}$. As $q_{2}=\frac{\left(a+\theta w_{1}-q_{1}-c-s\left(\varepsilon-w_{1}\right)\right)}{2}$, we can also get $q_{2}^{*}=\frac{\left(a+\theta w_{1}-c-s\left(\varepsilon-w_{1}\right)\right)}{4}$.

Substituting $q_{1}{ }^{*}$ and $q_{2}{ }^{*}$ into the profit functions, we can obtain

$$
\begin{aligned}
& \pi_{11}^{(1)}=\frac{\left(a+\theta w_{1}-c-s\left(\varepsilon-w_{1}\right)\right)^{2}}{8}-\frac{(1-r) k_{1} w_{1}^{2}}{2} \\
& \pi_{11}^{(2)}=\frac{\left(a+\theta w_{1}-c-s\left(\varepsilon-w_{1}\right)\right)^{2}}{16}-\frac{(1-r) k_{2} w_{1}^{2}}{2}
\end{aligned}
$$


Second, we assume that Group 2 first chooses radical innovation, and Group 1 then follows to choose radical innovation. We first obtain the partial derivative of $q_{1}$ for $\pi_{11}{ }^{(1)}$. Similarly, we can get

$$
q_{1}^{*}=\frac{\left(a+\theta w_{1}-c-s\left(\varepsilon-w_{1}\right)\right)}{4}, q_{2}^{*}=\frac{\left(a+\theta w_{1}-c-s\left(\varepsilon-w_{1}\right)\right)}{2}
$$

Substituting $q_{1}^{*}$ and $q_{2}^{*}$ into the profit functions, we can obtain

$$
\begin{aligned}
& \pi_{11}^{(1)}=\frac{\left(a+\theta w_{1}-c-s\left(\varepsilon-w_{1}\right)\right)^{2}}{16}-\frac{(1-r) k_{1} w_{1}^{2}}{2} \\
& \pi_{11}{ }^{(2)}=\frac{\left(a+\theta w_{1}-c-s\left(\varepsilon-w_{1}\right)\right)^{2}}{8}-\frac{(1-r) k_{2} w_{1}^{2}}{2}
\end{aligned}
$$

According to the model assumption, the two groups simultaneously choose radical innovation. That is, we suppose that the probability of the two manufacturers taking the lead in radical innovation is equal. We can obtain the profit functions based on the combination of the two situations above as follows:

$$
\begin{aligned}
& \pi_{11}^{(1)}=\frac{3\left(a+\theta w_{1}-c-s\left(\varepsilon-w_{1}\right)\right)^{2}}{32}-\frac{(1-r) k_{1} w_{1}^{2}}{2} \\
& \pi_{11}{ }^{(2)}=\frac{3\left(a+\theta w_{1}-c-s\left(\varepsilon-w_{1}\right)\right)^{2}}{32}-\frac{(1-r) k_{2} w_{1}^{2}}{2}
\end{aligned}
$$

The proof is complete.

\section{Appendix B}

When Group 1 adopts radical innovation and Group 2 adopts incremental innovation, the profit functions of the two manufacturers groups are as follows:

$$
\begin{aligned}
& \pi_{12}{ }^{(1)}=\left(a+\theta w_{1}-\left(q_{1}+q_{2}\right)\right) q_{1}-c q_{1}-s\left(\varepsilon-w_{1}\right) q_{1}-\frac{(1-r) k_{1} w_{1}^{2}}{2} \\
& \pi_{12}{ }^{(2)}=\left(a+\theta w_{2}-\left(q_{1}+q_{2}\right)\right) q_{2}-c q_{2}-s\left(\varepsilon-w_{2}\right) q_{2}-\frac{(1-r) k_{2} w_{2}^{2}}{2}
\end{aligned}
$$

We first obtain the partial derivative of $q_{2}$ for $\pi_{12}{ }^{(2)}$ as the manufacturer in Group 1 has the first-mover advantage in the game.

$$
\frac{\partial \pi_{12}{ }^{(2)}}{\partial q_{2}}=a+\theta w_{2}-q_{1}-2 q_{2}-c-s\left(\varepsilon-w_{2}\right)
$$

Let $\frac{\partial \pi_{12}{ }^{(2)}}{\partial q_{2}}=0$, and we can get $q_{2}=\frac{\left(a+\theta w_{2}-q_{1}-c-s\left(\varepsilon-w_{2}\right)\right)}{2}$.

Then $\pi_{12}{ }^{(1)}=\left(\frac{a+2 \theta w_{1}-\theta w_{2}-q_{1}+c+s\left(\varepsilon-w_{2}\right)}{2}\right) q_{1}-c q_{1}-s\left(\varepsilon-w_{1}\right) q_{1}-\frac{(1-r) k_{1} w_{1}{ }^{2}}{2}$,

$$
\frac{\partial \pi_{12}(1)}{\partial q_{1}}=\frac{\left(a+2 \theta w_{1}-\theta w_{2}+c+s\left(\varepsilon-w_{2}\right)-2 c-2 s\left(\varepsilon-w_{1}\right)\right)}{2}-q_{1}
$$

Let $\frac{\partial \pi_{12}(1)}{\partial q_{1}}=0$, we can get $q_{1}^{*}=\frac{\left(a+2 \theta w_{1}-\theta w_{2}-c-2 s\left(\varepsilon-w_{1}\right)+s\left(\varepsilon-w_{2}\right)\right)}{2}$.

As $q_{2}=\frac{\left(a+\theta w_{2}-q_{1}-c-s\left(\varepsilon-w_{2}\right)\right)}{2}$, we can get $q_{2}{ }^{*}=\frac{\left(a+3 \theta w_{2}-2 \theta w_{1}-c-3 s\left(\varepsilon-w_{2}\right)+2 s\left(\varepsilon-w_{1}\right)\right)}{4}$.

Then we can obtain the profit functions of two groups as follows:

$$
\begin{gathered}
\pi_{12}{ }^{(1)}=\frac{\left(a+2 \theta w_{1}-\theta w_{2}-c+s\left(\varepsilon-w_{2}\right)-2 s\left(\varepsilon-w_{1}\right)\right)^{2}}{8}-\frac{(1-r) k_{1} w_{1}{ }^{2}}{2} \\
\pi_{12}{ }^{(2)}=\frac{\left(a+3 \theta w_{2}-2 \theta w_{1}-c-3 s\left(\varepsilon-w_{2}\right)+2 s\left(\varepsilon-w_{1}\right)\right)^{2}}{16}-\frac{(1-r) k_{2} w_{2}^{2}}{2}
\end{gathered}
$$

The proof is complete. 


\section{Appendix C}

When Group 2 adopts radical innovation and Group 1 adopts incremental innovation, the profit functions of the two manufacturer groups are as follows:

$$
\begin{aligned}
& \pi_{21}{ }^{(1)}=\left(a+\theta w_{2}-\left(q_{1}+q_{2}\right)\right) q_{1}-c q_{1}-s\left(\varepsilon-w_{2}\right) q_{1}-\frac{(1-r) k_{1} w_{2}{ }^{2}}{2} \\
& \pi_{21}{ }^{(2)}=\left(a+\theta w_{1}-\left(q_{1}+q_{2}\right)\right) q_{2}-c q_{2}-s\left(\varepsilon-w_{1}\right) q_{2}-\frac{(1-r) k_{2} w_{1}{ }^{2}}{2}
\end{aligned}
$$

The same with the Appendixes above, we can get the following:

$$
\frac{\partial \pi_{21}(1)}{\partial q_{1}}=a+2 \theta w_{2}-2 q_{1}-q_{2}-c-s\left(\varepsilon-w_{2}\right)
$$

Let $\frac{\partial \pi_{21}(1)}{\partial q_{1}}=0, q_{1}=\frac{\left(a+\theta w_{2}-q_{2}-c-s\left(\varepsilon-w_{2}\right)\right)}{2}$.

$$
\begin{gathered}
\pi_{21}{ }^{(2)}=\left(a+\theta w_{1}-\left(\frac{q_{2}+a+\theta w_{2}-c-s\left(\varepsilon-w_{2}\right)}{2}\right)\right) q_{2}-c q_{2}-s\left(\varepsilon-w_{1}\right) q_{2}-\frac{(1-r) k_{2} w_{1}^{2}}{2} \\
\frac{\left.\partial \pi_{21}{ }^{2}\right)}{\partial q_{2}}=\frac{a+2 \theta w_{1}-\theta w_{2}+c+s\left(\varepsilon-w_{2}\right)}{2}-q_{2}-c-s\left(\varepsilon-w_{1}\right) \\
q_{1}^{*}=\frac{a+3 \theta w_{2}-2 \theta w_{1}-c-3 s\left(\varepsilon-w_{2}\right)+2 s\left(\varepsilon-w_{1}\right)}{4} \\
q_{2}^{*}=\frac{a+2 \theta w_{1}-\theta w_{2}-c-2 s\left(\varepsilon-w_{1}\right)+s\left(\varepsilon-w_{2}\right)}{2} \\
\pi_{21}{ }^{(1)}=\frac{\left(a+3 \theta w_{2}-2 \theta w_{1}-c-3 s\left(\varepsilon-w_{2}\right)+2 s\left(\varepsilon-w_{1}\right)\right)^{2}}{16}-\frac{(1-r) k_{1} w_{2}^{2}}{2} \\
\pi_{21}{ }^{(2)}=\frac{\left(a+2 \theta w_{1}-\theta w_{2}-c-2 s\left(\varepsilon-w_{1}\right)+s\left(\varepsilon-w_{2}\right)\right)^{2}}{8}-\frac{(1-r) k_{2} w_{1}^{2}}{2}
\end{gathered}
$$

The proof is complete.

\section{Appendix D}

When both groups adopt incremental innovation, there is no first-mover advantage in the game, the profit functions of the two manufacturer groups are as follows:

$$
\begin{aligned}
& \pi_{21}{ }^{(1)}=\left(a+\theta w_{2}-\left(q_{1}+q_{2}\right)\right) q_{1}-c q_{1}-s\left(\varepsilon-w_{2}\right) q_{1}-\frac{(1-r) k_{1} w_{2}{ }^{2}}{2} \\
& \pi_{22}{ }^{(2)}=\left(a+\theta w_{2}-\left(q_{1}+q_{2}\right)\right) q_{2}-c q_{2}-s\left(\varepsilon-w_{2}\right) q_{2}-\frac{(1-r) k_{2} w_{2}{ }^{2}}{2}
\end{aligned}
$$

According to rule of Cournot model,

$$
\begin{aligned}
& \frac{\partial \pi_{22}(1)}{\partial q_{1}}=a+\theta w_{2}-2 q_{1}-q_{2}-c-s\left(\varepsilon-w_{2}\right) \\
& \frac{\partial \pi_{22}(2)}{\partial q_{2}}=a+\theta w_{2}-q_{1}-2 q_{2}-c-s\left(\varepsilon-w_{2}\right)
\end{aligned}
$$

Let $\frac{\partial \pi_{22}{ }^{(1)}}{\partial q_{1}}=0$ and $\frac{\partial \pi_{22}(2)}{\partial q_{2}}=0$, we can get

$$
\begin{gathered}
q_{1}^{*}=\frac{a+\theta w_{2}-c-s\left(\varepsilon-w_{2}\right)}{3}, q_{2}^{*}=\frac{a+\theta w_{2}-c-s\left(\varepsilon-w_{2}\right)}{3} \\
\pi_{22}{ }^{(1)}=\frac{\left(a+\theta w_{2}-c-s\left(\varepsilon-w_{2}\right)\right)^{2}}{9}-\frac{(1-r) k_{1} w_{2}{ }^{2}}{2} \\
\pi_{22}{ }^{(2)}=\frac{\left(a+\theta w_{2}-c-s\left(\varepsilon-w_{2}\right)\right)^{2}}{9}-\frac{(1-r) k_{2} w_{2}{ }^{2}}{2}
\end{gathered}
$$


The proof is complete.

\section{References}

1. Li, F.; Dong, S.; Li, X.; Liang, Q.; Yang, W. Energy consumption-economic growth relationship and carbon dioxide emissions in China. Energy Policy 2011, 39, 568-574.

2. Zhu, G.; Pan, G.; Zhang, W. Evolutionary Game Theoretic Analysis of Low Carbon Investment in Supply Chains under Governmental Subsidies. Int. J. Environ. Res. Public Health 2018, 15, 2465. [CrossRef] [PubMed]

3. Yan, X.; Fang, Y.-P. $\mathrm{CO}_{2}$ emissions and mitigation potential of the Chinese manufacturing industry. J. Clean. Prod. 2015, 103, 759-773. [CrossRef]

4. Lin, B.; Li, X. The effect of carbon tax on per capita $\mathrm{CO}_{2}$ emissions. Energy Policy 2011, 39, 5137-5146. [CrossRef]

5. He, S.; Yin, J.; Zhang, B.; Wang, Z. How to upgrade an enterprise's low-carbon technologies under a carbon tax: The trade-off between tax and upgrade fee. Appl. Energy 2018, 227, 564-573. [CrossRef]

6. Du, S.; Zhu, J.; Jiao, H.; Ye, W. Game-theoretical analysis for supply chain with consumer preference to low carbon. Int. J. Prod. Res. 2015, 53, 3753-3768. [CrossRef]

7. Zhang, B.; Bi, J.; Yuan, Z.; Ge, J.; Liu, B.; Bu, M. Why do firms engage in environmental management? An empirical study in China. J. Clean. Prod. 2008, 16, 1036-1045. [CrossRef]

8. Gualandris, J.; Kalchschmidt, M. Customer pressure and innovativeness: Their role in sustainable supply chain management. J. Purch. Supply Manag. 2014, 20, 92-103. [CrossRef]

9. Huang, X.-X.; Hu, Z.-P.; Liu, C.-S.; Yu, D.-J.; Yu, L.-F. The relationships between regulatory and customer pressure, green organizational responses, and green innovation performance. J. Clean. Prod. 2016, 112, 3423-3433. [CrossRef]

10. Yenipazarli, A. Incentives for environmental research and development: Consumer preferences, competitive pressure and emissions taxation. Eur. J. Oper. Res. 2019, 276, 757-769. [CrossRef]

11. Bi, G.; Jin, M.; Ling, L.; Yang, F. Environmental subsidy and the choice of green technology in the presence of green consumers. Ann. Oper. Res. 2017, 255, 547-568. [CrossRef]

12. Hansen, E.G.; Große-Dunker, F. Sustainability-Oriented Innovation; Springer: Berlin/Heidelberg, Germany, 2013.

13. Klewitz, J.; Hansen, E.G. Sustainability-oriented innovation of SMEs: A systematic review. J. Clean. Prod. 2014, 65, 57-75. [CrossRef]

14. Xue, M.; Boadu, F.; Xie, Y. The Penetration of Green Innovation on Firm Performance: Effects of Absorptive Capacity and Managerial Environmental Concern. Sustainability 2019, 11, 2455. [CrossRef]

15. Nidumolu, R.; Prahalad, C.K.; Rangaswami, M.R. Why sustainability is now the key driver of innovation. Harv. Bus. Rev. 2009, 87, 56-64.

16. Yang, L.; Hao, X.; Zhang, X.; Yuan, S. What matters for carbon emissions in regional sectors? A China study of extended STIRPAT model. J. Clean. Prod. 2018, 180, 595-602. [CrossRef]

17. Li, N.; Chen, W. Modeling China's interprovincial coal transportation under low carbon transition. Appl. Energy 2018, 222, 267-279. [CrossRef]

18. Wang, C.; Nie, P.-Y.; Peng, D.-H.; Li, Z.-H. Green insurance subsidy for promoting clean production innovation. J. Clean. Prod. 2017, 148, 111-117. [CrossRef]

19. Shen, L.; Zhang, Z.; Zhang, X. Key factors affecting green procurement in real estate development: A China study. J. Clean. Prod. 2017, 153, 372-383. [CrossRef]

20. Levinthal, C.D.A. Special Issue: Technology, Organizations, and Innovation || Absorptive Capacity: A New Perspective on Learning and Innovation. Adm. Sci. Q. 1990, 35, 128-152.

21. Zhang, Y.; Sun, J.; Yang, Z.; Li, S. Organizational Learning and Green Innovation: Does Environmental Proactivity Matter? Sustainability 2018, 10, 3737. [CrossRef]

22. Bernauer, T.; Engel, S.; Kammerer, D.; Sejas Nogareda, J. Explaining Green Innovation: Ten Years after Porter's Win-Win Proposition: How to Study the Effects of Regulation on Corporate Environmental Innovation? Soc. Sci. Electron. Publ. 2007, 39, 323-341.

23. Bergek, A.; Berggren, C. The impact of environmental policy instruments on innovation: A review of energy and automotive industry studies. Ecol. Econ. 2014, 106, 112-123. [CrossRef] 
24. Xin, Z.; Sun, B. The influence of Chinese environmental regulation on corporation innovation and competitiveness. J. Clean. Prod. 2016, 112, 1528-1536.

25. Krass, D.; Nedorezov, T.; Ovchinnikov, A. Environmental Taxes and the Choice of Green Technology. Prod. Oper. Manag. 2013, 22, 1035-1055. [CrossRef]

26. Hinloopen, J. Subsidizing R\&D-Cooperatives. Economist 2001, 149, 313-345.

27. Wang, Y.; Chang, X.; Chen, Z.; Zhong, Y.; Fan, T. Impact of subsidy policies on recycling and remanufacturing using system dynamics methodology: A case of auto parts in China. J. Clean. Prod. 2014, 74, 161-171. [CrossRef]

28. Porter, M.E. Green and competitive ending the stalemate. Harv. Bus. Rev. 1995, 28, 128-129.

29. Bansal, P.; Roth, K. Why Companies Go Green: A Model of Ecological Responsiveness. Acad. Manag. J. 2000, 43, 717-736.

30. Huang, Z.; Liao, G.; Li, Z. Loaning scale and government subsidy for promoting green innovation. Technol. Forecast. Soc. Chang. 2019, 144, 148-156. [CrossRef]

31. Leeuwen, G.V.; Mohnen, P. Revisiting the Porter hypothesis: An empirical analysis of Green innovation for the Netherlands. Merit Work. Pap. 2013, 67, 295-319. [CrossRef]

32. Acemoglu, D.; Akcigit, U.; Hanley, D.; Kerr, W.R. Transition to Clean Technology. Harv. Bus. School Work. Pap. 2014, 124, 15-45.

33. Chen, Z.-Y.; Nie, P.-Y. Effects of carbon tax on social welfare: A case study of China. Appl. Energy 2016, 183, 1607-1615. [CrossRef]

34. Dzonzi-Undi, J.; Li, S. Policy Influence on Clean Coal Uptake in China, India, Australia, and USA. Environ. Prog. Sustain. Energy 2016, 35, 906-913. [CrossRef]

35. Wanting, C.; Zhi-Hua, H. Using evolutionary game theory to study governments and manufacturers' behavioral strategies under various carbon taxes and subsidies. J. Clean. Prod. 2018, 201, 123-141.

36. Jian-Zhong, X.U.; Guan, J.; Zhu, X.Y. Evolutionary Game Analysis on Impacts of Government Regulation on Enterprises' Environmental Innovation Mode Selection. Oper. Res. Manag. Sci. 2017, 26, 68-77.

37. Chang, C.H. The Influence of Corporate Environmental Ethics on Competitive Advantage: The Mediation Role of Green Innovation. J. Bus. Ethics 2011, 104, 361-370. [CrossRef]

38. Schiederig, T.; Tietze, F.; Herstatt, C. Green innovation in technology and innovation management-An exploratory literature review. $R$ D Manag. 2012, 42, 180-192. [CrossRef]

39. Chen, Y.S.; Lai, S.-B.; Wen, C.-T. The Influence of Green Innovation Performance on Corporate Advantage in Taiwan. J. Bus. Ethics 2006, 67, 331-339. [CrossRef]

40. He, X.; Dai, H.; Peng, N. Faster Learning and Adaptation in Security Games by Exploiting Information Asymmetry. IEEE Trans. Signal Process. 2016, 64, 3429-3443. [CrossRef]

41. Wang, Q.; Tan, Z.; De, G.; Tan, Q.; Pu, L. An Evolutionary Game Study of Clean Heating Promotion Mechanisms under the Policy Regulation in China. Sustainability 2019, 11, 3778. [CrossRef]

42. Zhu, Q.H.; Dou, Y.J. Evolutionary Game Model between Governments and Core Enterprises in Greening Supply Chains. Syst. Eng. 2007, 27, 85-89. [CrossRef]

43. Zhao, R.; Zhou, X.; Han, J.; Liu, C. For the sustainable performance of the carbon reduction labeling policies under an evolutionary game simulation. Technol. Forecast. Soc. Chang. 2016, 112, 262-274. [CrossRef]

44. Mahmoudi, R.; Rasti-Barzoki, M. Sustainable supply chains under government intervention with a real-world case study: An evolutionary game theoretic approach. Comput. Ind. Eng. 2018, 116, 130-143. [CrossRef]

45. Sheng, G.H.; Zhang, Z.Y.; School, B.; University, J.; Accounting, S.O. Allowance method's influence on the innovation model choice in evolutionary game. J. Manag. Sci. China 2015, 18, 34-45.

46. Cachon, G.P.; Lariviere, M.A. Supply Chain Coordination with Revenue-Sharing Contracts. Manag. Sci. 2005, 51, 30-44. [CrossRef]

47. Xu, X.; Ping, H.; Hao, X.; Zhang, Q. Supply chain coordination with green technology under cap-and-trade regulation. Int. J.Prod. Econ. 2017, 183, 433-442. [CrossRef]

48. D'Aspremont, C.; Jacquemin, A. Cooperative and Noncooperative R\&D in Duopoly with Spillovers. Am. Econ. Rev. 1988, 78, 1133-1137.

49. Amir, R. Modelling Imperfectly Appropriable R\&D via Spillovers. Int. J. Ind. Organ. 2000, 18, $1013-1032$.

50. Matsumura, T.; Matsushima, N. Endogenous Cost Differentials between Public and Private Enterprises: A Mixed Duopoly Approach. Economica 2010, 71, 671-688. [CrossRef] 
51. Hofbauer, J.; Sigmund, K. Evolutionary game dynamics. Bull. Am. Math. Soc. 2003, 40, 479-519. [CrossRef]

52. Friedman; Daniel, Evolutionary Games in Economics. Econometrica 1991, 59, 637-666. [CrossRef]

53. Taylor, P.D.; Jonker, L.B. Evolutionarily stable strategies and game dynamics. Math. Biosci. 1978, 40, 145-156. [CrossRef]

(c)

(C) 2020 by the authors. Licensee MDPI, Basel, Switzerland. This article is an open access article distributed under the terms and conditions of the Creative Commons Attribution (CC BY) license (http://creativecommons.org/licenses/by/4.0/). 